\title{
Diplomatic Mandela calls for action on HIV...
}

Michael Cherry, Cape Town

It was not a formal rebuke. But former South African president Nelson Mandela last week came as close as politically possible to chastising his successor, Thabo Mbeki, for re-opening the debate on whether HIV causes AIDS.

Delivering the closing address at the 13th International AIDS Conference in Durban on Sunday, Mandela urged that this debate be "put on the back-burner, so that we can address the needs of those who are suffering and dying".

He added: "History will judge us harshly unless we do so right now." A week earlier, Mbeki's opening address to the conference - in which he refused to respond to demands that he accept the current scientific wisdom on the HIV/AIDS link — had received a hostile reception from many of the 12,500 attending (see Nature 406, 113; 2000).

"I do not doubt," said Mandela, "that President Mbeki will proceed with the resolve for which he is known. The challenge is to move from rhetoric to action on an unprecedented scale."

Mandela went on to describe measures to prevent mother-to-child transmission of HIV as "essential", following the examples of Uganda, Senegal and Thailand.

This statement - again an implicit criticism of the South African government's procrastination - was met by tumultuous applause. It also brought a broad smile from conference chairman Jerry Coovadia, professor of paediatrics at the University of Natal, sitting behind the former president on the platform.

"Mandela has raised the debate to a level considered impossible before his arrival at the conference," said Coovadia. So far, the South African government has refused to

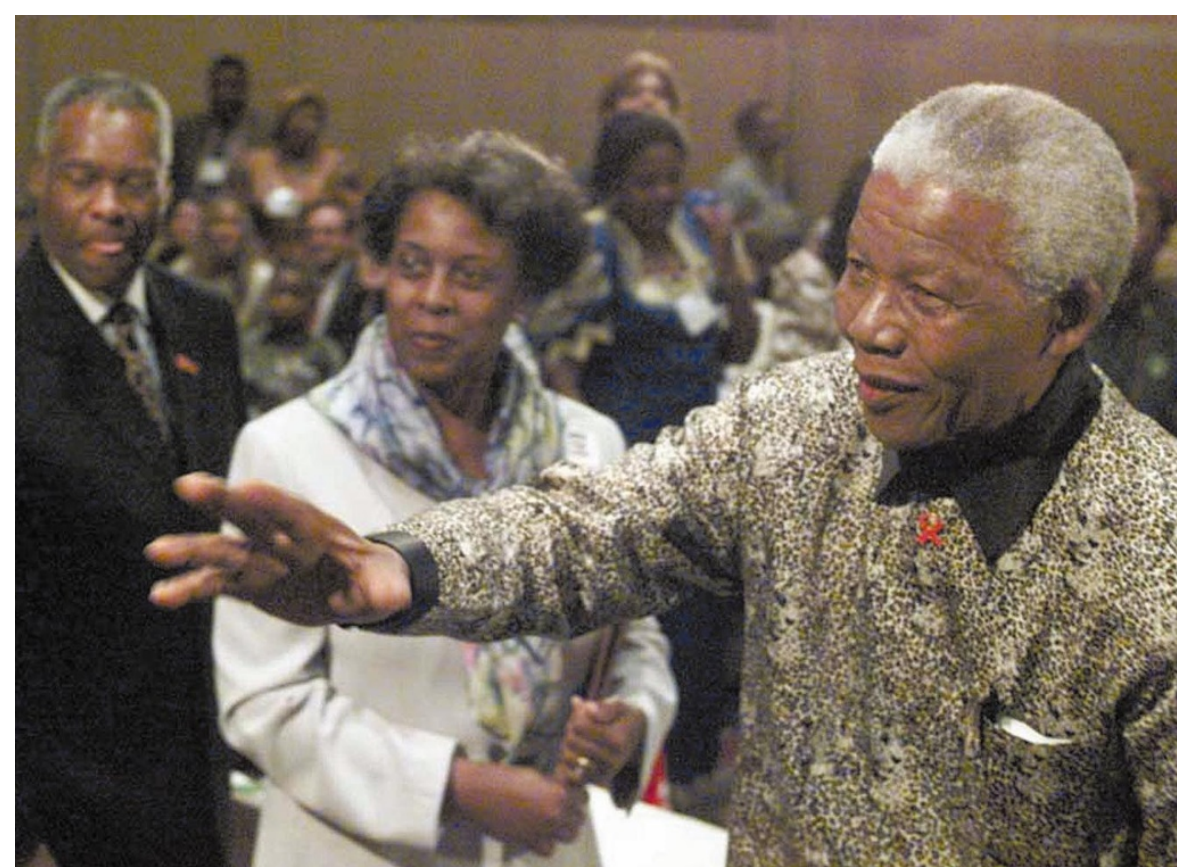

A stronger hand: Mandela arrives at the Durban meeting, where he appealed for an end to rhetoric.

introduce an antiretroviral programme for HIV-positive mothers, voicing concern about the toxicity and price of such drugs (see below).

Mandela appears to be the only person in the African National Congress, the main party in the government, with the authority to criticize Mbeki. As such, his comments may prompt a change of heart among cabinet ministers, most of whom have kept silent on the issue.

His remarks will also increase pressure on the government from its own health officials. Many of these are frustrated with Mbeki's stance, arguing that it has held back a commitment to preventing the spread of HIV.

Ayanda Ntsaluba, director-general in the
Department of Health, stated at a press briefing earlier last week that his department would consider implementing an antiretroviral programme for pregnant women as soon as it had received two relevant reports. One of these covers recent trials conducted in the country on the antiretroviral drug nevirapine, the results of which were presented at the conference. The second looks at the obstacles to implementation, based on a study being conducted in the Cape Town township of Khayelitsha.

He stressed that implementation of the programme was not linked to the findings of Mbeki's advisory panel on AIDS, which the president indicated in his address would report back only at the end of the year.

\section{... as South Africa considers its options after free drugs offer}

Nevirapine's low price and simplicity of administration - it requires only two doses to the pregnant mother, and one to the infant after delivery - has made it a popular antiretroviral drug for preventing mother-to-child transmission of HIV in developing countries.

But the role of pharmaceutical companies remains controversial. On the eve of last week's AIDS conference in Durban (see above) the drug's manufacturer, Boehringer Ingelheim, offered to provide it free to 100 developing countries for five years, as long as they could demonstrate both that they needed the drug and that they had the infrastructure to administer its provision.

But the offer met with a frosty reception from South African health minister Manto Tshabalala-Msimang, who criticized the company for not telling the government about its offer before the announcement.

Boehringer Ingelheim's representative in South Africa, Lynette Boshoff, told Nature that no governments wereapproached before the offer was made, and that negotiations would start immediately after the conference with those that were interested in taking it up.

Representatives from Boehringer Ingelheim and four other drug companies and agencies in the Access to Treatment initiative (see Nature 405, 263; 2000) met with government officials from across Africa including Tshabalala-Msimang — in Geneva on 30 June to discuss providing developing countries with cut-price drugs. Boehringer Ingelheim's gffer appears to supersede this in the case of nevirapine.
The meeting followed an official approach to the targeted countries, including South Africa, by United Nations agencies to determine whether they wished to investigate the offer. A second meeting is expected to be held in September.

Meanwhile, Tshabalala-Msimang continues to emphasize that South Africa is considering parallel importation (procurement from channels not authorized by the patent holder), and compulsory licensing, although neither option now appears necessary in the case of nevirapine. 